\title{
LA INFLUENCIA DE LAS RADIOS Y LAS TELEVISIONES COMUNITARIAS EN LA CONS- TRUCCIÓN DE LA CIUDADANÍA
}

\author{
Francisco Collado Campaña \\ (Universidad Pablo de Olavide) \\ f_collado_c@hotmail.com
}

\section{Resumen:}

La aparición de una tipología de medios de comunicación, televisiones y radios adscritas a la sociedad civil, ha favorecido la construcción de la ciudadanía en Europa. Asimismo, la ruptura de los monopolios audiovisuales, la descentralización mediática y la redefinición de unos medios comunitarios propios de la ciudadanía representan la lucha de los colectivos sociales para obtener una autonomía comunicativa con respecto a las instancias públicas. De esta forma, los países europeos con un sistema democrático y un mayor bienestar como Suecia, Holanda y Francia han comenzado a contemplar la existencia de una categoría de medios propios para los colectivos cívicos.

Palabras clave: Medios comunitarios, democracia participativa, comunidad, ciudadanía, Europa.

\begin{abstract}
:
The appearance of a tipology of mass media, televisions and radios assigned to the civil society, has favored the construction of the citizenship in Europe. Also, the rupture of the audio-visual monopolies, the mediatic decentralization and the redefinition of own communitarian means of the citizenship represent the fight of the social groups to obtain a communicative autonomy with respect to the public instances. Of this form, the European countries with a democratic system and a greater well-being like Sweden, Holland and France have begun to contemplate the existence of an own means category for the civic groups.
\end{abstract}

Key words: Communitarian media, participative democracy, community, citizenship, Europe.

\section{LA CONQUISTA CIUDADANA DE LOS MEDIOS DE COMUNICACIÓN}

\subsection{La sociedad civil y su nuevo contexto en las transformaciones políticas}

a sociedad civil es un concepto replanteado actualmente debido al aumento del peso del colectivo cívico y la limitación de la soberanía del Estado -exactamente el tercer sector para diferenciar a la misma ciudadanía del ámbito público y del privado-, tal y como lo entienden Arbós y Giner (2002: 21). Bajo este 
término es como han denominado algunos autores (Hegel, 1975) al sustrato humano que tiene como objeto organizar el Estado occidental. Las transformaciones políticas y sociales sufridas en los últimos tiempos han supuesto una reestructuración en la constante comunicación mantenida entre las instancias públicas y dicha ciudadanía. En esta conexión han cobrado una especial importancia los medios de comunicación y de información, pues este flujo de conocimientos es plenamente endógeno. Se produce una retroalimentación comunicativa, tal y como lo entiende el sistema político ${ }^{1}$ de David Easton (1969: 221), entre los demandantes y sus representantes políticos. Desde este proceso, el resultado que comienza por la base y asciende hasta la cima vuelve a confluir hasta dicho punto inicial, dando como resultado una respuesta del Estado a la consulta o petición planteada. Así, la sociedad civil entendida en esta perspectiva comunicativa plantea una serie de retos en el sentido de encontrar un equilibrio entre la gobernación de sus miembros y la garantía de ofrecerles la participación en la res pública a la mayoría de éstos. La necesidad de los medios de comunicación los convierte en receptáculos ideales de este mensaje que se desprende de la sociedad civil hasta sus representantes políticos.

La sociedad civil también presupone una división que utiliza como criterio diferenciador la propiedad de un objeto que sólo admite dos únicos propietarios. Y en este sentido, la misma ciudadanía que no participa en estos sectores queda excluida, sin reconocimiento. Además, es imposible establecer una separación exacta de los miembros de una sociedad en función de su papel como propietarios, sobre todo en las actuales democracias occidentales (Rodríguez Prieto, 2005: 20-21). Por tanto, para hablar de la ciudadanía y del papel que juegan en este proceso de diálogo con el Estado, sería más apropiado emplear otro concepto. Para ello, hablaremos exactamente de comunidad para señalar a este actor del proceso de comunicación que recibe un estímulo del órgano que la gestiona, el Estado, según las peticiones que formula.

La comunidad en este fenómeno de comunicación ha comenzado a experimentar en los últimos años las deficiencias de las democracias nacionales representativas (Soriano, 2002), y en contraposición más que en complementación, surgen las iniciativas de democracia participativa o directa. Puesto que en el ámbito local ya no se hace tan necesario acudir a los representantes, sobre todo cuando los mismos individuos están comenzando a diseñar las políticas locales. No falte citar ejemplos como el Comité del Gran Londres o las asambleas ciudadanas que se constituyen en los distritos de los municipios españoles. Por lo tanto, esta comunicación jerárquica propia del sistema político tiende a volverse horizontal en el ámbito local. En este proyecto de autogobierno, empleamos el término de demoarquía (Rodríguez Prieto, 2005: 73) para definir estas iniciativas llevadas a cabo desde la comunidad para establecer su gestión autónoma en su entorno local y con un carácter igualitario entre sus miembros con respecto a eliminar su dependencia de una comunicación jerárquica con el Estado en dichos asuntos de interés cercano.

\footnotetext{
${ }^{1}$ El concepto de sistema político ha supuesto un instrumento recurrente de la politología contemporánea para explicar los fenómenos dinámicos de comunicación en las democracias contemporáneas. Este esquema de comunicación manifiesta un proceso jerárquico y circular, por el que los ciudadanos plantean una demanda a sus gobernantes para posteriormente recibir una respuesta, fruto del proceso de deliberación política. Esto responde claramente al funcionamiento de la democracia representativa.
} 
La comunidad como actora del proceso de comunicación horizontal que inaugura la demoarquía exige la necesidad de unos medios de comunicación propios que sirvan como instrumentos de difusión y desarrollo humano, tal y como entiende el profesor de periodismo Manuel Chaparro (2002: 57-58). De este modo, éstos dejan de prestar un servicio público para convertirse en un instrumento democrático, es decir, de todo el conjunto humano de una localidad. Este instrumental implica, para autores como Mario Kaplún (1998) y Paulo Freire (1986), un proceso de liberación mediante la enseñanza de los medios y su empleo en la formación de las personas. La demoarquía como proceso horizontal, de igual a igual, requiere no ya sólo esa equidad en el acto comunicativo, sino también un proceso de educación desde un educando a otro educando ${ }^{2}$ como ruptura con el sistema tradicional de relación entre maestro y alumno ${ }^{3}$ para gestionar los asuntos de su agenda política. Así, en esta autonomía que se comienza a adquirir de los ejecutivos centrales, es fundamental el enriquecimiento que se puede producir entre las distintas experiencias de los miembros de la comunidad, consiguiendo escapar al posible riesgo que entrañase la tutela de una elite auspiciada por los comicios electorales. En esta confluencia entre la democracia participativa local y la exigencia de unos medios de comunicación que potencien cualitativamente dicha experiencia surgen las radios y las televisiones comunitarias.

La característica de la democracia como un fenómeno de sinergia exige de esa readaptación de la relación mantenida entre la comunidad y sus representantes, como se ha comentado anteriormente. En este sentido, Jesús Timoteo Álvarez (en Chaparro, 1998: 20) apunta que las radios locales poseen unas ventajas sinérgicas que fomentan el desarrollo local y mejoran la información de los colectivos más acostumbrados a conocer una realidad circundante que la propia. Por ello, es preferible que estos medios sirvan como canales del mensaje de los ciudadanos en este nuevo contexto de comunicación social. A diferencia de la persuasión comercial o negativa ${ }^{4}$ de los medios de masas ${ }^{5}$, desde los medios locales comunitarios asistimos a una persuasión positiva en palabras de Álvarez. Este beneficio es el primer síntoma de la influencia enriquecedora de los medios comunitarios en la ciudadanía, desde un punto de vista teórico. Una segunda ventaja, es la posibilidad de compactar a las comunidades a nivel geográfico generando una producción multimedia propia y alternativa a los contenidos de los medios masivos. Ello favorecería una barrera a los efectos perniciosos de la globalización en cuanto a su proceso de uniformidad de valores.

\footnotetext{
${ }^{2}$ Freire habla de educando, en gerundio, antes que de un educador y un educado para manifestar el proceso pedagógico como un hecho con vigencia en el presente.

${ }^{3}$ El conocimiento no puede ser el trasvase de información desde un objeto hacia otro, sino entre éstos mutuamente al comunicarse entre sí al hacer frente a un problema común.

${ }^{4}$ Negativa en cuanto que no admite o no reconoce una respuesta directa del receptor, a excepción de la posible compara de un producto determinado.

5 Denominaremos como medios de masas a los medios de comunicación comerciales o privados cuyo fin descansa en la maximización de los beneficios obtenidos. Lo que implica que no se pueden reconocer como auténticos medios de comunicación, puesto que Chaparro sostiene que, para reafirmarse como tales, deberían permitir una respuesta por parte del público que no se redujese a la adquisición de un bien o a su exposición a un espacio publicitario.
} 


\subsection{El cuarto poder en manos de la ciudadanía}

Pero antes de conocer el auténtico calado de estas iniciativas de comunicación es necesario definir claramente el concepto de medios de comunicación comunitarios, así como conocer cuál ha sido su origen histórico, para diferenciarlos claramente de los medios del sector público y los medios de masas. Podemos decir, con precisión, que las radios y las televisiones comunitarias son las iniciativas audiovisuales de carácter local desarrolladas por comunidades y colectivos ciudadanos con una clara vocación de servicio a la sociedad (Gumucio, 2002), destinados a generar contenidos de calidad y de interés ciudadano, con un funcionamiento y una administración democráticos que ofrezcan un lugar para la participación de cualquier miembro de la comunidad en el diseño y la difusión del mensaje y eviten su restricción al papel de receptor pasivo. El objetivo es producir el despertar de una voluntad cívica activa que hasta ese momento había permanecido callada, solapada y olvidada por las autoridades públicas y los medios de masas. Lo que tiene su origen en el carácter alternativo y alterativo ${ }^{6}$ de estos medios. El fin primordial de estos medios descansaría sobre la necesidad de la construcción de una ciudadanía que orientase sus pasos hacia la consolidación de una sociedad democrática, no sobre el criterio de maximización de beneficios (Villamayor y Lamas, 1998: 216). Y en ese sentido, los medios de comunicación comunitarios cumplirían con el auténtico papel que se espera de dichos medios al servir como vehículos para la articulación del conjunto del sustrato humano con respecto a su participación activa en el entorno local.

El concepto anteriormente planteado se puede considerar un cuarto poder más allá de la clásica división formulada por Montesquieu, al actuar como fiscalizadores del poder ejecutivo y altavoces de la oposición en el legislativo (Cotarelo, 1998). Lo que no han logrado plenamente los medios masivos, que han permanecido en más de una ocasión defendiendo los intereses particulares de los partidos políticos y las organizaciones comerciales. Pero este control del gobierno no se efectúa sirviendo como tribuna de la oposición política, sino como púlpito para la ciudadanía por encima del partidismo y de la ideología.

Una vez que conocemos este hecho, cabe preguntarse, ¿cuándo nacen estas iniciativas mediáticas originadas en el seno de la ciudadanía? O, mejor dicho, ¿en qué momento se produce la apropiación de los medios de comunicación por parte de la ciudadanía? Desde el contexto europeo, el monopolio de la televisión y la radio eran una medida de seguridad que se mantenía desde la II Guerra Mundial para evitar la caída en un nuevo episodio de propaganda totalitaria (Chaparro, 2002: 68), como ya habían experimentado anteriormente los vencedores con el sistema propagandístico nazi de Goebbels. Con ello, la conclusión de los aliados manifestaba que los medios debían cumplir una función de servicio público y que la libertad debía mantenerse a toda costa para la supervivencia del sistema político occidental. Pero esta pluralidad representaba una libertad destinada a un objeto y, además, una responsabilidad social y una vigilancia, lo que impedía dejar estos instrumentos en manos de una ciudadanía aún no lo suficientemente madura para acceder a ellos, un hecho

\footnotetext{
${ }^{6}$ Chaparro habla de las radios alterativas más que alternativas como aquéllas que tienen como objeto no sólo construir la ciudadanía, sino alterarla de modo que mejore su situación cualitativamente y la desarrolle mediante la transformación social que fomentan con su programación. Es una visión basada en la postura del profesor Rafael Roncagliolo, presidente de AMARC.
} 
que afectó en mayor grado a la España franquista (Díaz Nosty, 1987). La ruptura de este status quo no se produce exactamente con la pérdida de este miedo, sino que es fruto de las facilidades tecnológicas. Por tanto, el abaratamiento de los costes de los requerimientos tecnológicos permitió el inicio de las radiodifusiones piratas ${ }^{7}$ en Holanda, Dinamarca y Gran Bretaña a mediados del siglo XX. Posteriormente, y en consecuencia, surgieron las radios libres en Italia y Francia durante los setenta y el gobierno sueco impulsaba la política de Allemansradio con la instalación de estaciones de escasa potencia en la frecuencia modulada para su administración por las comunidades.

La mayoría de estas emisoras tuvieron que luchar contra la imagen de alegalidad que presentaban ante las autoridades públicas y la reducida capacidad de sus recursos tecnológicos. Esto permitió que con el paso de las décadas se reservasen algunos espacios del espectro radioeléctrico para sus emisiones, así como que se elaborase una reglamentación que las contemplase legalmente como una categoría más de medios de comunicación. En este sentido, las radios y las televisiones comunitarias comparten con los movimientos sociales (ecologismo, feminismo, abstencionismo, nuevas tendencias socialistas) el objetivo de alterar la situación presente del estado liberal-democrático de cara a ampliar la calidad de vida de los ciudadanos con la lucha social como instrumento legítimo de movilización (Exeni, 1998). De este modo, la actual situación es considerada tan sólo un punto de partida para pasar de fiscalizadores de una democracia representativa ${ }^{8}$ hacia su papel como actores en una democracia participativa. Así, el éxito se produce desde el instante en que las sociedades descubren los mecanismos para acabar con la imposición de los instrumentos de miedo, dominación y terror, de la misma forma que entiende Rafael Rodríguez (2002: 12).

Como última anotación cabría citar que la apropiación de estos medios representa tanto una necesidad técnica como historicista. Si recordamos, el pensamiento socialista ha permanecido durante mucho tiempo centrado en la conquista de los medios de producción industriales, pero lo que no tuvo en cuenta fue que paralelamente a este acceso de las personas a los bienes y servicios era necesario que se produjese otro similar. Y si tenemos en cuenta que la información equivale al poder y es incluso una exigencia democrática en palabras de Coolt (en Chaparro, 2002: 68), también debía de darse esa entrada de los individuos a los recursos de creación de los mensajes que estructuran la sociedad. Por ello, durante mucho tiempo las autoridades han impedido el acceso de las personas a estos recursos comunicativos. Tan sólo la reestructuración de las relaciones sociales a partir de los setenta ha permitido la contraposición de esta nueva fórmula de comunicación horizontal ciudadana frente a la comunicación vertical dominante, algo que coincide paralela y temporalmente, con la oposición entre la democracia participativa local ante la democracia representativa nacional, asistiendo así a una coyuntura de evolución fruto de un doble antagonismo que se alimenta causalmente.

\footnotetext{
7 Se denominan piratas no ya por su ilegalidad, sino porque en un principio estas emisoras operaban desde embarcaciones situadas en las aguas internacionales donde no eran accesibles a las autoridades estatales.

${ }^{8}$ La anteposición entre democracia representativa y participativa, equivale respectivamente a la competencia entre dos modelos de democracia, uno indirecto mediante el anonimato del sufragio periódico y otro directo con la participación de los consejos cívicos.
} 


\section{LAS RADIOS Y LAS TELEVISIONES COMUNITARIAS EN EUROPA}

La influencia de los medios de comunicación en la articulación de la ciudadanía europea no puede ser desdeñada. Si tenemos en cuenta que el temor de la ruptura de los monopolios mediáticos era el temor al resurgimiento de una nueva ola totalitarista, no podemos negar que este miedo era el mismo de la dictadura de una mayoría (los ciudadanos) frente a una minoría (la clase política). Dicho de otra forma, era el tradicional miedo a la democracia de los sistemas parlamentarios con concepciones distintas del Estado liberal (Constant, 1998). Lo que afortunadamente para los analistas conservadores no se cumplió tanto como actualmente se produce la tiranía inversa desde las corporaciones mediáticas como Murdoch y Berlusconi (Sánchez, 1993), por citar algunos.

La aparición de estos medios alternativos en el entorno local supone sin duda, una progresión natural en las sociedades desarrolladas del entorno europeo (Chaparro, 1998: 30). Lo que implica, una mejora cualitativa de la salud de las democracias tradicionales y su revalorización en el panorama de la globalización que hace surgir a nuevos actores sociales. Además, la explicación de que los medios comunitarios son en la mayoría de los casos audiovisuales permite la captación de un fragmento de la población al que no se llegaría a través de la prensa9 ${ }^{9}$.

Las radios comunitarias europeas son en algunos casos el equivalente a las emisoras públicas locales de Estados Unidos. Estas televisiones y radios se agrupan en la National Public Radio (NPR) y la Federación Nacional de Radiodifusores Comunitarios (NFCB). De esta forma, lo comunitario se entiende como público. Cuestión que no se cumple en Europa donde existen dos modelos exactos de emisoras públicas: las emisoras públicas como las municipales españolas y las de carácter asociativo o comunitario. Pese a ello, se aprecian diferencias en función de los colectivos que gestionan las radios y el país donde se establecen. En este sentido, Peter Lewis, ha contabilizado en Europa más de 1.500 emisoras comunitarias y otras 800 en eclosión (Chaparro: 1998: 52-54).

El desarrollo de las iniciativas mediáticas comunitarias así como sus consecuencias entre la ciudadanía y los países europeos abren un espacio para la geopolítica de la comunicación de las comunidades europeas. Por ello, a continuación abordaremos la situación particular de estas radios y televisiones en cada uno de los Estados del viejo continente.

\subsection{Gran Bretaña}

El desarrollo de las experiencias radiales locales tiene su origen en una red de emisoras en complicidad con entidades locales que propició la BBC tras evaluar su déficit de información de interés cercano. En cualquier caso, el experimento británico es el más parecido al modelo español, por cuanto que el programa más solicitado a las emisoras comunitarias son los informativos de carácter regional. Estas emisoras se encuentran en localidades como Londres, Birminghan y Manchester, mientras

\footnotetext{
9 Un estudio realizado en 1984 para conocer las preferencias de los jóvenes mostraba cómo el $49 \%$ y el $23 \%$ preferían respectivamente el consumo del medio televisión y radio.
} 
que otras más reducidas se ubican en Oxford, Caslisle y Blackburn. Una de las críticas contra el modelo local de la BBC reside en los agentes locales, que ponen en duda la falta de independencia de estas emisoras (Chaparro, 1998: 59). Lo que es competencia del IBA en realidad. Este organismo vigila el cumplimiento de una normativa estricta orientada a impedir que el sentido local de estas emisoras se vea modificado.

\subsection{Francia}

El referente italiano y británico son los dos justificantes que explican la reivindicación antimonopolio de las emisoras libres. Sólo a partir de 1982, con el gobierno socialista, se conceden 22 frecuencias de carácter ciudadano. Y la legislación promulgada por los socialistas desde el año anterior ha permitido según fuentes de AMARC la consolidación de 500 radios asociativas. Con todo ello, el caso francés es uno de los modelos más ilustrados por los autores en el panorama europeo, debido a su producción legislativa en esta materia (Sánchez, 1996).

Actualmente estas emisoras libres son denominadas como asociativas, y cada vez ofrecen un servicio más valorado al ocupar un espacio despreciado por otras estaciones comerciales (Chaparro, 1998: 55). En otras palabras, aquellos núcleos de población con un escaso número de habitantes como para satisfacer los intereses publicísticos de las radios privadas, son cubiertos por emisoras propias con una finalidad netamente social y ciudadana. Un ejemplo manifiesto es la emisora de la localidad Marné-la-Vallé que comenzó en 1990, y que según su director tiene una clara vocación en la integración de la población extranjera. Así, la radio comunitaria francesa tiene un papel fundamental en la integración de los inmigrantes.

Aun así, algunas emisoras libres legalizadas entre 1982 y 1983 han acabado pasándose al otro bando, y se han integrado en estructuras de medios comerciales. El Consejo Superior Audiovisual, una autoridad pública independiente, es la encargada de entregar estas licencias, así como las ayudas económicas que se desprenden de un sistema de impuestos sobre los ingresos por publicidad de las emisoras convencionales. Asimismo, estas emisoras se agrupan en colectivos como el Consejo Nacional de Radios Asociativas y la Confederación Nacional de Radios Libres.

En palabras de Manuel Chaparro, lo más destacable de la situación francesa es la obtención de fondos a partir de los ingresos por publicidad convencional, lo que le otorga una gran independencia administrativa a sus miembros de cara a fomentar la participación ciudadana y política. No obstante, últimamente no se estaba cumpliendo con el gobierno francés durante el año 2002, con la no observancia de la Ley Trautmann que prevé dicho fondo desde las emisoras comunitarias.

\subsection{Holanda}

Holanda se nutre de un total de 376 emisoras de comunidad reguladas por el gobierno, de las que casi un tercio poseen un carácter multimedia ${ }^{10}$ con sus equiva-

\footnotetext{
$\overline{10}$ El fenómeno multimedia implica la tendencia a reunir las distintas modalidades técnicas de los medios de comunicación en sus formatos de prensa, radio, televisión y portales web. Esto favorece la expansión de los grupos de comunicación en todas las vertientes del sector de la comunicación.
} 
lentes en televisión e Internet. Estas iniciativas tienen su origen en la subvención del gobierno holandés de seis canales experimentales de radio y televisión en el ámbito local entre 1974 y 1978. Desde estas emisoras, se constituiría la Organisatie van Lokale Omroepen in Nederland (OLON), que comenzaría como promotora de los intereses locales.

Las emisiones cubren a localidades de cien mil habitantes, pero también se encuentran en núcleos más reducidos. Además, las organizaciones con licencia para la radiodifusión local también la poseen para las emisiones especializadas. Asimismo, sólo las organizaciones sin ánimo de lucro pueden obtener licencias de emisión local.

Legalmente, la ley holandesa exige la creación de un órgano de participación, compuesto por representantes de distintos sectores sociales, culturales, políticos y religiosos, que supervisan la programación. En cuanto a su financiación es mixta, con aportaciones públicas, patrocinios, suscripciones al coste de un euro por hogar y mediante inserciones publicitarias. Es preciso apuntar, además, la cobertura de enriquecimiento ciudadano (Chaparro, 2002: 86) de estas emisoras que dan trabajo a más de 500 personas y se nutren del trabajo de 20.000 voluntarios.

\subsection{Bélgica}

El gobierno de la comunidad valona (francófona) ha favorecido la creación de la Federación de Televisiones Locales y Regionales de la Comunidad Francesa. Con ello, aporta un total de once canales que están administrados por asociaciones privadas sin ánimo de lucro. Asimismo, la financiación está asegurada por los poderes públicos de la comunidad francófona, y en menor cuantía por los ingresos de la producción y la publicidad. De aquí que el papel de las minorías y los medios comunitarios estén unidos por la necesidad de ofrecer un espacio de emisión para estos colectivos, cuya presencia en los espacios televisivos es reducida por los medios generalistas (Núñez, 2003). En este sentido, la formación de estos medios sirve como un medio de defensa de la identidad nacional. Frente a ello, la comunidad flamenca ha comenzado a poner en funcionamiento determinadas emisoras de habla neerlandesa, aunque sin la existencia de una regulación técnica por parte del gobierno belga.

\subsection{Suecia}

El parlamento sueco creó en 1977 una serie de veinticuatro radios locales con niveles provinciales de cobertura. Los objetivos consistían en difundir información, aumentar el nivel de conocimiento y enriquecer el debate público. Estas iniciativas se agrupaban en la LRAB, propiedad de Sveriges Radio. Desde estas emisoras se crearon subestaciones, centros de producción y de difusión. Así, un total de 15 municipios iniciaron sus emisiones en 1978. Su gestión recae en comités locales independientes del gobierno. El objetivo de estas políticas era conseguir la mayor participación posible de la sociedad civil, rompiendo con el temor de los peligros del monopolio estatal en los medios. En pocas palabras, su intención era aumentar la autonomía de la sociedad civil mediante un proceso descentralizador (Qvortrup, 1981). 
Por medio de este sistema, toda persona jurídica sin intereses lucrativos o partidistas podía acceder, previa solicitud, al derecho de emisión en estos canales. Autores como Miller (1987), califican a la Allemansradio como la radio de todos, por ser un modelo de democracia participativa y de descentralización. Aunque este modelo se halla actualmente en crisis debido a los recortes en las subvenciones municipales.

\subsection{España}

El primer precedente que encontramos se ubica en la localidad andaluza de Pozoblanco (Chaparro, 1998: 63) en 1974. Esta emisora tiene su origen en la red de emisoras parroquiales que se habían ofrecido a la Conferencia Episcopal con la firma del Concordato entre la Santa Sede y España en 1953 por el colaboracionismo durante la Guerra Civil. Y es que, cinco años más tarde, el interés del gobierno por acabar con estas emisoras, que exigían el derecho a un canal de radio propio, llevaría al nacimiento de Radio Popular.

La emisora de Pozoblanco prosiguió sus radiaciones hasta 1965, cuando desparece como víctima de los planes de viabilidad de la Cadena de Ondas Populares Españolas (COPE). Aún así, la población cordobesa no se resignó a la pérdida de su emisora. Por ello, el 18 de mayo de 1971, el Director General de Radio y Televisión, Adolfo Suárez, comunicaba la concesión de licencia para una emisora de frecuencia modulada. Finalmente, la puesta en marcha no se produciría hasta 1974.

Sólo la llegada de la democracia permitió que otras localidades, con una antigua radio parroquial, reivindicasen su recuperación. Un caso es la Voz de los Pedroches, que es una emisora de recursos autosuficientes con una implantación en su comarca. O por ejemplo, cabe citar la evolución de Radio Dalías en el municipio almeriense del mismo nombre, que fue reabierta con un interés comercial en 1975, pero posteriormente ante el riesgo de una clausura gubernativa en 1984, el municipio accedió a gestionar la emisora. Aunque todo quedó en el gesto, y no se volvió a emitir hasta un año después. Otros casos son el municipio malagueño de Alhaurín El Grande en la provincia de Málaga y Onda Puerto Radio, en la capital malacitana.

La Asociación de Radios Comunitarias de España (ARCE) es el órgano que reúne a estas emisoras. La mayoría de éstas son emisoras de barrio como Radio Enlace, Onda Merlín, Radio Vallekas y Radio Utopía, entre otras tantas de Madrid; el caso de Radio Pika en Cataluña y Radio Klara en Valencia.

Un ejemplo de asociacionismo y de participación horizontal lo observamos en EMA-RTV, la corporación de radios y televisiones comunitarias andaluzas que colabora abiertamente con la organización mundial de asociativas, AMARC ${ }^{11}$, tras la consolidación de un acuerdo en Jerez de la Frontera en 1996. Esto les ha permitido enriquecerse no ya sólo con su producción, sino con otros contenidos de producción horizontal que provienen de otras localidades foráneas saltando las barreras fronterizas.

\footnotetext{
11 AMARC, la Asociación Mundial de Radios Comunitarias, es el movimiento internacional que agrupa a las radios comunitarias y a los movimientos ciudadanos con experiencias radiofónicas. Su objetivo es democratizar las comunicaciones para favorecer el desarrollo equitativo y las libertades de expresión.
} 
La influencia de las radios y televisiones comunitarias en la construcción de la ciudadanía

\subsection{Dinamarca}

La legislación danesa (Chaparro: 1998, 62) ha permitido la concesión de licencias de radio a las autoridades locales, pero con el objeto de facilitar las actividades de producción y de emisión a los ciudadanos. Asimismo, las experiencias de emisoras locales participativas han comenzado en 1983, y en un solo año han consolidado un centenar de emisoras.

\section{LA CONSTRUCCIÓN DE LA CIUDADANÍA EUROPEA MEDIANTE EL MEN- SAJE COMUNITARIO}

El desarrollo de los medios comunitarios en Europa juega una gran importancia en la construcción de una ciudadanía europea. Desde la perspectiva de la investigación en comunicación, para responder a estos interrogantes sería adecuado acudir a la extensa literatura disponible sobre el estímulo de los receptores mediante el consumo del contenido mediático, pero estos análisis han estado siempre sesgados por una visión elitista, basada en la psicología conductista ${ }^{12}$ y con una clara pretensión comercial cuyo auténtico fin era conocer las preferencias consumistas del público. Por ello, Chaparro propone una visión más abierta, más liberalizadora que no reduzca al ciudadano a su papel de emisor, ya que en este espacio local es donde los emisores pueden participar de los contenidos que ellos mismos han producido. Así, se percibe cómo los ciudadanos participantes en los medios comunitarios son tanto emisores como receptores, lo que favorece la retroalimentación comunicativa en una relación de plena horizontalidad. Ello da lugar a una gestión del medio por la comunidad independientemente de su participación económica en la empresa y fomenta un medio de movilización cívica. En este sentido, y si volvemos, sobre las características de la demoarquía, el funcionamiento interno de estas radios y televisiones locales concuerda con los requerimientos propios de esta nueva forma de democracia directa. Rodríguez (2002) manifiesta que el propiciar una democracia participativa supone los siguientes cambios:

1. Una participación activa, a lo que da lugar el mensaje cívico de estos medios mediante la percepción de la realidad cercana antes que la circundante. Así se puede observar cómo la comunidad valona ha fomentado estas experiencias para reafirmar su identidad francófona frente a la población neerlandesa en Bélgica.

2. Una producción socialmente útil, en cuanto que se producen unos contenidos de calidad, de interés cercano, alternativos a las radiofórmulas comerciales y orientados hacia un target ${ }^{13}$ objetivo que es a la vez productor y consumidor, igualando las fuerzas de la demanda y la oferta que difícilmente se ajustan en los medios de

\footnotetext{
12 La teoría de la aguja hipodérmica y el esquema comunicativo generado por Laswell durante la década de los veinte desde la comunicación política han tenido un gran impacto por su carácter patriarcal y jerárquico desde sus orígenes. Lo que se manifestó en la aplicación de estos estudios en el diseño de las campañas electorales y publicitarias norteamericanas durante las primeras décadas del siglo pasado. En definitiva, dotaban de una gran importancia a la capacidad de control del emisor sobre el receptor, antes que resaltar la posibilidad de retroalimentación comunicativa que más tarde rescataría Schramm.
}

${ }^{13}$ En la terminología de los mass media, el target representa el público objetivo hacia el que se dirige un programa o un contenido publicitario. En nuestro caso estudiado, el target sería la misma comunidad. 
masas. Este caso se vislumbra claramente en la cantidad de voluntarios que sostienen los multimedia comunitarios en Holanda.

3. Asimismo, se produce una sinergia en cuanto las mismas fuerzas activadoras de la voluntad cívica son las que ejecutan, difunden y consumen el mensaje. Lo que fomenta la alteración de la relación vertical entre la comunidad y el Estado tendente hacia una horizontalidad que concuerda con la característica de la democracia participativa. Sin duda, este último proceso ha sido el más difícil en países como España ${ }^{14}$.

No cabe duda de que las exigencias de la fórmula de la democracia directa local y los medios comunitarios se complementan perfectamente, para dar lugar a una ciudadanía más informada y madura que la mantenida en la clásica comunicación jerárquica de las democracias representativas nacionales. Y así, no ya sólo desde la postura de la comunicación, sino además desde la visión de la ética y el pensamiento político y moral en torno a los medios de comunicación se destaca la capacidad de los medios audiovisuales para devolver el protagonismo perdido por la ciudadanía en el ámbito comunicativo. Autores como Jesús Conil y Vicent Gozálvez (2004: 28-30) afirman que es preciso, en este sentido, favorecer la consolidación de centros mediáticos y de asociaciones de consumidores que expresen su opinión para enriquecer aún más la capacidad crítica contra los medios masivos desde los medios locales. Desde esta lectura, se desprende un aumento de la capacidad de elección de los ciudadanos, así como se obliga a algunos grupos a manifestar su línea ideológica en pro de una mayor objetividad. En estas sociedades de ciudadanos se resalta el papel de estos medios en la vertebración de una sociedad civil madura unida por asociaciones, dispuestos a participar en la esfera pública de cara a discutir lo justo y lo injusto. Y según Conil y Gozálvez, de no auspiciarse estos multimedia comunitarios no encontraríamos ciudadanos, sino vasallos de cualquier representante o poder fáctico que tenga la posibilidad de mantener su soberanía mediante los medios de masas.

Esta necesidad de estos medios audiovisuales coincide con el debate de exclusión/inclusión que vive actualmente la ciudadanía (Facultad de Comunicación de Puerto Rico, 2005: 7). Autores latinoamericanos, como Erick Torrico, añaden que esta democratización de los medios ha sido una línea desarrollada en América Latina y Europa, pero indica que ahora es necesario recorrer una línea paralela a los medios comunitarios mediante la comunicabilidad de la democracia. En otras palabras, que el mensaje no sólo debe ser realizado desde la comunidad, sino que debe aludir al funcionamiento inherente de ésta y ser coherente con dicha democracia participativa, ofreciendo un mensaje alternativo y enriquecedor a los consumos comerciales que ofrecen los medios masivos (Facultad de Comunicación de Puerto Rico, 2005: 31-42). Así, se deduce que en muchos países como España e Italia no se ha producido aún esta comunicación del mensaje democrático, sino que los contenidos han llegado a asemejarse a las radiofórmulas comerciales de las radios y las televisiones comerciales. Por tanto, no siempre se ha producido un estallido favora-

\footnotetext{
14 La mayoría de las emisoras comunitarias de capital no público y mantenidas por los colectivos ciudadanos no son contempladas en la legislación española, que aún permanece estancada para ofrecer una regulación. Asimismo, tampoco se les ofrecen ventajas ni se reserva una cuota del espacio radioeléctrico para su emisión.
} 
La influencia de las radios y televisiones comunitarias en la construcción de la ciudadanía

ble de los proyectos radiales comunitarios. Así, existe una democracia incomunicada, que según Torrico es una causa del divorcio entre los parlamentarios y la comunidad representada, por el que la democracia se transforma en una administración inservible y corrupta, que coloca en un margen al demos. En conclusión, esta democracia no puede desarrollarse en plenitud con unas líneas de comunicación interrumpidas por los fracasos de estas experiencias comunitarias de construcción del mensaje.

La concienciación de la comunidad supone otro de los valores que rescata la radio local, según Chaparro, ya que el derecho a la información favorece su conciencia en dos sentidos, tanto en el acceso a la información como en el proceso de su selección para difundirla a través de los canales. De esta selección, se produce un aumento de la objetividad (Chaparro, 1998: 32-35), pues los medios locales producen una imagen de la ciudadanía cotidiana, de sus quehaceres y su ámbito más cercano alejados de la hiperinformación nacional e internacional propia de los medios de comunicación. Así, para autores como Peces Barba, las consecuencias inmediatas de la lectura del mensaje es el aumento de la independencia del individuo como comunicador y una mejora de la administración. Por tanto, puede afirmarse que conforme se define el ámbito del ciudadano como comunicador se mejoran cualitativa y cuantitativamente las respuestas de las instancias públicas a los inputs políticos. En conclusión, es esa reestructuración de los hilos comunicativos del sistema político que adelantaba Easton.

La influencia de estos medios en las identidades nacionales también es una consecuencia directa de esta reafirmación de la persona como emisora. En aquellos países donde existen grupos que manifiestan su pertenencia a distintas nacionalidades, los medios comunitarios favorecen su revalorización evitando ese ajuste perfecto entre Estado y nación en pro de su reajuste entre territorio y comunidad humana. De esta forma, se difunde la lengua, la cultura y las costumbres locales frente a la uniformidad de los rasgos etnoculturales planteados desde el grupo que gestiona el aparato estatal.

Una coincidencia interesante de los beneficios democráticos de estos medios comunitarios es que dicha concienciación de los ciudadanos en su papel activo y la necesidad de incorporar una barrera a la manipulación de los grupos mediáticos ha coincidido con el control del poder ejecutivo por parte del poder legislativo en la España democrática. Además, el aumento de estas cuotas de libertad de comunicación favorece el autogobierno desde la administración local. Así, la actitud crítica de la comunidad intenta sustituir la función de fiscalización del poder de un gobierno que ahora controla al legislativo mediante las mayorías disciplinadas.

Por último, y en conclusión, puede afirmarse que se producen unos beneficios manifiestos de estas experiencias de radios y televisiones gestionadas desde la sociedad civil en Europa, pero siempre entendidos en pro de la construcción de la ciudadanía. Así, estas ventajas son de distinta índole, según Chaparro (1998: 38):

1. Beneficios políticos y sociales: La descentralización de los medios de comunicación se produce como un proceso paralelo a la descentralización política. De esta forma, los medios comunitarios se convierten en un factor destinado a realizar prestaciones sociales y apoyar el Estado de Bienestar. 
2. Beneficios económicos: La producción socialmente útil se refleja en los consejos cívicos que asesoran a estos medios ciudadanos.

3. Beneficios asociativos: Los ciudadanos dejan de ser receptores autónomos para convertirse en emisores unidos.

4. Beneficios en el ejercicio de la ciudadanía (Villamayor y Lamas, 1998: 223-224): Adelantan el paso de una democracia representativa a otra de ejercicio directo y acorde con la participación. Estas emisoras locales favorecen la participación del individuo en las decisiones que le afectan y la defensa de los intereses comunes. Ernesto Lamas (1998) entiende que la ciudadanía también supone la lucha, la controversia y la toma de posiciones de cara a mejorar los intereses individuales y colectivos.

5. Beneficios tecnológicos: Una redefinición de la demanda de instrumentos de producción y difusión favorece la celeridad de la transformación tecnológica en el ámbito de la ciudadanía.

Por tanto, los medios de comunicación comunitarios, más allá de su beneficio en la ciudadanía, de su concordancia con las exigencias y las necesidades de la democracia participativa local, suponen unos instrumentos de desarrollo humano ${ }^{15}$. $Y$ este desarrollo siempre se genera de una forma acorde con la comunidad en la que se inserta, lo que, por tanto, niega la existencia de un procedimiento exacto y determinado que debiera ser implantado por igual en todos los colectivos de ciudadanía.

\section{CONCLUSIONES}

En ese sentido, este desarrollo de la comunicación y su investigación debiera dirigirse hacia la democratización en la práctica del discurso y la horizontalidad de la comunicación entre los individuos. Este desarrollo humano, en opinión de Ramiro Beltrán (en Chaparro, 2002: 59-61), se transmite mediante tres perspectivas:

1. La comunicación de desarrollo como la influencia en la modificación de las actitudes (persuasión positiva) con objeto de crear un contexto favorable al cambio. Un ejemplo típico son las campañas de sensibilización en materia de drogas y malos tratos.

2. La comunicación de apoyo al desarrollo como contenidos que favorecen cualitativamente el mismo ejercicio del cambio social como la educación mediante las telenovelas que trabajó Mario Kaplún.

3. La comunicación para el desarrollo como último estadio de apropiación de los medios por parte de la sociedad civil o la comunidad ciudadana.

Esta consideración de la comunicación como herramienta del desarrollo aún no termina de vislumbrarse en Europa donde aún impera la restricción del elemento co-

\footnotetext{
15 El desarrollo humano que señalamos no es el definido por los criterios económicos que divide a los países en desarrollados y subdesarrollados, sino que nos referimos al potencial de desarrollo social, cultural y político, que posea toda comunidad que no ha explotado al máximo sus posibilidades.
} 
La influencia de las radios y televisiones comunitarias en la construcción de la ciudadanía

municativo como servicio público. Algunos ejemplos de experiencias en pro de este desarrollo se observa en la disminución de la marginalidad en los barrios periféricos de Medellín en Colombia (Chaparro, 1997: 61-68), donde las bandas de jóvenes enfrentados han comenzado a gestionar y producir una programación propia que les une al hablar de sus problemas comunes en el día a día. También cabría citar las grandes posibilidades de las emisoras educativas que comienzan con la iniciativa de radio Sutatenza en Colombia y las radios mineras en Bolivia durante la década de los cincuenta. Y hasta en los últimos años, un fenómeno avanzado es la aplicación de este desarrollo de la comunicación mediante las tecnologías multimedia en el ámbito de la educación universitaria en América Latina, como es el caso de la Universidad Nacional de Córdoba en Argentina (Chaparro, 1999: 241-249). A través de esta emisora, se ofrecen una serie de cursos televisivos, que posteriormente eligen la audiencia que son los alumnos.

Por tanto, las últimas décadas han servido tan sólo como momento de incubación de los primeros proyectos europeos de iniciativas radiales y televisivas comunitarias. Sus ventajas todavía están por explotar y explorar por la sociedad civil, siempre en constante disputa con la competencia ejercida desde las corporaciones tendentes a la concentración multimedia. Por eso, es preciso defender al ciudadano de estos grupos de comunicación, en la medida que en los medios locales el individuo recupera su poder frente a la concentración de la soberanía en el ejecutivo y las deficiencias de representatividad del legislativo. El ciudadano se convierte así en fiscalizador de los tres poderes, se personifica la comunidad y se defienden sus intereses. En definitiva, el ciudadano/actor/activo despierta como un elemento vivo del que se espera una acción fáctica, lógica y racional como respuesta al mensaje comunitario recibido.

No obstante, este éxito sólo es el punto de partida, pues la reducción de los ingresos publicitarios, la pobreza de los contenidos y el escaso alcance de su campo de emisión son algunos de los problemas que padecen estos medios de comunicación ciudadanos en su eclosión inicial.

\section{REFERENCIAS BIBLIOGRÁFICAS}

ARBÓS, X.; GINER, S. La gobernabilidad: ciudadanía y democracia en la encrucijada mundial. Madrid: Siglo XXI de España Editores, 2002.

BERLÍN, I. "Radio, los medios de servicio público, América y Europa: apuntes para un diagnóstico". Revista Latina de Comunicación Social, (1998) n 7, pp. 1-8.

CHAPARRO M. Sorprendiendo al futuro. Comunicación para el desarrollo e información audiovisual. Barcelona: Los Libros de la Frontera, 2002.

- (1999) La democratización de los medios. Sevilla: Diputación de Sevilla.

- (1998) Radio pública local. Sevilla: Editorial Fragua.

- (1997) Radiotelevisión pública local y alternativa: perspectivas. Sevilla: Diputación de Sevilla. 
CONILL, J.; Gozálvez, V. Ética de los medios: una apuesta por la ciudadanía audiovisual. Barcelona: Editorial Gedisa, 2004.

CONSTANT, B. Del espíritu de conquista. Madrid: Tecnos, 1998.

COTARELO, R.; CUEVAS, J. A. El cuarto poder: medios de comunicación y legitimación democrática en España. Melilla: UNED, 1998.

DíAZ NOSTY, B. Los medios y la hipótesis de la democracia degradada. Málaga: Universidad de Málaga, 1995.

- (1987) Historia del franquismo. Barcelona: Argos Vergara.

EASTON, D. Enfoques sobre teoría política. Buenos Aires: Amorrortu, 1969.

EXENI, J. L. Políticas de Comunicación: retos y señales para no renunciar a la utopía. La Paz: Plural, 1998.

FACULTAD DE COMUNICACIÓN DE PUERTO RICO. Comunicación, democracia y ciudadanía. Puerto Rico: Universidad de Puerto Rico, 2005.

FREIRE, P. La naturaleza política de la educación: cultura, poder y liberación. Barcelona: Paidós, 1990.

- (1986) La educación como práctica de la libertad. Madrid: Siglo XXI.

GUMUCIO, A. Haciendo olas: historia de la comunicación participativa para el cambio cocial. Bogotá (Ecuador): La Iniciativa de Comunicación, 2002 [consulta de 2 de mayo de 2008. Disponible en<http://www.comminit.com/es/node/150011>

HEGEL, G. W. F. Principios de filosofía del derecho. Buenos Aires: Editorial Sudamericana, 1975.

KAPLÚN, M. Una pedagogía de la comunicación. Madrid: La Torre, 1998.

MILLER, J. "Cuando el mercantilismo ahoga la información radiofónica local". Telos, (1987) $n^{\circ}$ 9, pp. 12-23.

NUÑEZ, S. "Minorías nacionales y medios de comunicación: una visión de Europa". Ámbitos: revista internacional de comunicación, (2003), nº 9-10, pp. 9-30.

QVORTRUP, L. "Democratization through local radio? A project on the descentralization of radio broadcasting in Scandinavia". Nordicom Review, (1981) n 1, pp. 1920.

RODRÍGUEZ PRIETO, R. Construyendo democracia: una propuesta para el debate. Sevilla: Aconcagua, 2005.

SÁNCHEZ, A. Concentració de la comunicació a Europa. Barcelona: Centro d'Investigació en Comunicació, 1993. 
La influencia de las radios y televisiones comunitarias en la construcción de la ciudadanía

SÁNCHEZ. S. Los medios de comunicación y los sistemas democráticos. Barcelona: Marcial Pons, 1996.

SORIANO, R. Democracia vergonzante y ciudadano de perfil. Granada: Comares, 2002.

VILLAMAYOR, C.; LAMAS, E. Gestión de la radio local y comunitaria. Quito: AMARC, 1998.

\section{Breve semblanza del autor}

Francisco Collado Campaña (Málaga, 1984) es Licenciado en Periodismo por la Universidad de Málaga, Máster en la Unión Europea por el Instituto Europeo 'Campus Stellae' y, actualmente, cursa los estudios de la licenciatura en Ciencias Políticas y de la Administración en la Universidad Pablo de Olavide. Desde finales de 2002, ha ejercido como periodista para Onda Puerto Radio, Canal Sur Radio, Diario Sur, Punto Radio y Utrera Ya. Es investigador colaborador en politología para el Grupo de Investigación Avanzada J.B. Conant del Colegio Complutense en Harvard, colabora en la publicación El Avisador Malagueño de la Academia de las Artes y las Letras Santa María de la Victoria y como columnista en Diario La Torre.

(Recibido el 9-05-07, aceptado el 23-04-08) 